2005-01-01

\title{
Temperature Dependent Spectroscopic Studies of HiPco SWNT Composites
}

\author{
Sinead Keogh \\ Technological University Dublin \\ Theresa Hedderman \\ Technological University Dublin, Theresa.Hedderman@tudublin.ie \\ Garrett Farrell \\ Technological University
}

See next page for additional authors

Follow this and additional works at: https://arrow.tudublin.ie/materart

Part of the Physical Sciences and Mathematics Commons

\section{Recommended Citation \\ This Article is brought to you for free and open access by the Materials Synthesis and Applications at ARROW@TU Dublin. It has been accepted for inclusion in Articles by an authorized administrator of ARROW@TU Dublin. For more information, please contact arrow.admin@tudublin.ie, aisling.coyne@tudublin.ie, gerard.connolly@tudublin.ie.}

Keogh, S., Heddermann, T.G. \& Farrell, G.F. (2005). Temperature Dependent Spectroscopic Studies of HiPco SWNT Composites. Synthetic Metals, vol. 154, pg.197-200. doi:10.1016/j.synthmet.2005.07.049

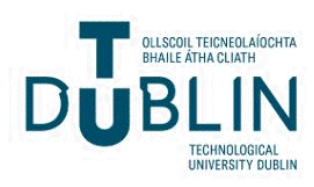




\section{Authors}

Sinead Keogh, Theresa Hedderman, Garrett Farrell, M Ruether, Elizabeth Gregan, Mary McNamara, Gordon Chambers, and Hugh Byrne 


\title{
Temperature Dependent Spectroscopic studies of HiPco SWNT composites.
}

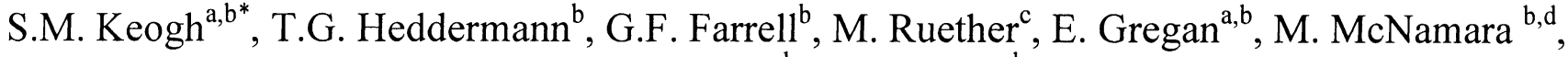 \\ G. Chambers ${ }^{\mathrm{a}, \mathrm{b}}$, H.J. Byrne $\mathrm{e}^{\mathrm{a}, \mathrm{b}}$ \\ ${ }^{a}$ School of Physics, Dublin Institute of Technology, Kevin Street, Dublin 08, Ireland \\ ${ }^{b}$ FOCAS, Dublin Institute of Technology, Kevin Street, Dublin 08, Ireland \\ ${ }^{c}$ Materials Ireland Polymer Research Centre, Department of Physics, Trinity College Dublin 08, Ireland, \\ ${ }^{d}$ School of Chemistry, Dublin Institute of Technology, Kevin Street, Dublin 8, Ireland
}

\begin{abstract}
Hybrid systems of the conjugated organic polymer poly(p-phenylene vinylene-co-2,5-dioctyloxy-m-phenylene vinylene)(PmPV) and HiPco SWNTs are explored using spectroscopic and thermal techniques to determine specific interactions. Vibrational spectroscopy indicates a weak interaction and this is further elucidated using Differential Scanning Calorimetry, Temperature Dependent Raman Spectroscopy and Temperature Dependent Infrared Spectroscopy of the raw materials and the composite. An endothermic transition is observed in the DSC of both the polymer and the $0.1 \%$ HiPco composite in the region of $60^{\circ} \mathrm{C}$. Also observed in the DSC of the composite is a doubly peaked endotherm at $-39^{\circ} \mathrm{C}$ and $-49^{\circ} \mathrm{C}$, which does not appear in the polymer film. The Raman of the polymer backbone upon increasing the temperature to $60^{\circ} \mathrm{C}$ shows diminished phenyl $\mathrm{A}_{\mathrm{g}}$ modes at $1557 \mathrm{~cm}^{-1}$ and $1575 \mathrm{~cm}^{-1}$, with an increase in the relative intensity of the vinyl mode at $1630 \mathrm{~cm}^{-1}$. This change in the Raman of the polymer is translated to the Raman of the composite upon increase to $60^{\circ} \mathrm{C}$, where the spectrum becomes abruptly dominated by nanotubes. The Raman of the composite shows no change in the lower temperature regions, however infrared suggests that the transition at $-39^{\circ} \mathrm{C}$ derives from an interaction with the polymer side chains. The composite at $-39^{\circ} \mathrm{C}$ shows a change in the absorption of the polymer side chain aryl-oxide linkage at $1250 \mathrm{~cm}^{-1}$, while Raman suggests a change to the polymer backbone configuration at $60^{\circ} \mathrm{C}$. Implications are discussed.
\end{abstract}

Keywords: Semi-comjugated polymers, SWNT Composites, Differential Scanning Calotimetry, Infrared and Raman Spectroscopy

\section{Introduction}

Carbon nanotubes exhibit many unique physical and chemical properties [1]. Due to the electronic and mechanical properties of nanotubes, polymer composites containing tubes have been recently investigated for improved electrical conductivity, optical devices and high strength fibers $[2,3]$. Thus much work has been done on the investigation of the nature of the interaction within polymer nanotube composites [4-7]. In one proposed system, specific interactions between PmPV and nanotubes have been reported [4-6]. The chemical structure of PmPV has been shown to allow solubility due to the presence of floppy side chains and conjugation along the polymers backbone [5]. The PmPV backbone reorganises into a relatively flat helical structure due to the $m$-phenelylene linkage and the repulsive interaction between the octyloxy side groups.

*Corresponding author. Tel: +353-1-4023000; fax: +353-14029999 E-mail: sinead.keogh@dit.ie

0379-6779/\$ - see front matter (C) 2005 Elsevier B.V. All rights reserved. doi:10.1016/j.synthmet.2005.07.049
It has been shown that the exposure of the backbone plays an important role in facilitating dipolar binding between the polymer and the nanotube, allowing the polymer to $\pi$ stack onto the nanotube backbone [5]. The trans linkage in the repeat unit is of particular importance, which inhibits polymer aggregation, as all cis conformations have been shown to cause polymer aggegation and inhibit interaction with the nanotube. In this paper to further investigate these systems films of $0.1 \% \mathrm{wt} \mathrm{HiPco} / \mathrm{PmPV}$ are investigated using temperature dependent (TD-) vibrational spectroscopy and Differential Scanning Calorimetry (DSC).

\section{Experimental}

The HiPco SWNTs (obtained from CNI Houston) $(0.1 \%$ by weight) were mixed in solutions of PmPV(1g/litre) in toluene as in reference 6 . DSC measurements were made using a Perkin Elmer Pyris Diamond power compensated DSC. The samples, $0.1 \% \mathrm{HiPco} / \mathrm{PmPV}$ ( $\sim 5 \mathrm{mg})$ dry composite were placed in closed platinum iridium 
crucibles and each sample was run twice (heat at $40^{\circ} \mathrm{C} / \mathrm{min}$ ). Raman spectra were obtained using an Instruments SA LabRam IB system. The confocal imaging system uses an argon ion source at $514.5 \mathrm{~nm}$. For infrared measurements, samples were drop cast onto slides and spectra were obtained in reflection mode using a Perkin Elmer Spectrum GX FT-IR microscope. Each system was fitted with a Linkam LNP cooling stage for temperature dependent measurements. Measurements were taken every 10 minutes at $5^{\circ} \mathrm{C}$ intervals from $-100^{\circ} \mathrm{C}$ to $130^{\circ} \mathrm{C}$. For Raman measurements the laser was switched off in between samplings. The system was cycled through twice in the same fashion as the DSC to ensure changes in the spectra were reversible or not where the case may be, as discussed in the following section.

\section{Results and Discussion}

Differential Scanning Calorimetry (DSC) was used to probe the SWNT-PmPV interaction. In fig 1, a broad endotherm is observed in the PmPV thermogram at $51^{\circ} \mathrm{C}$ in the temperature range of $-60^{\circ} \mathrm{C}$ to $130^{\circ} \mathrm{C}$, showing $\mathrm{PmPV}$ is semi-crystalline with some degree of order [8]. Introduction of nanotubes shows a similar transition although an increase in the peak temperature to $53^{\circ} \mathrm{C}$ is observed, which has been reported previously using MWNT composites [8]. Here it has been suggested via spectroscopic analysis as well as microscopy that the nanotubes can act as a template upon which the polymer can self-assemble, consequently increasing the crystallinity of the polymer film at ambient temperatures.
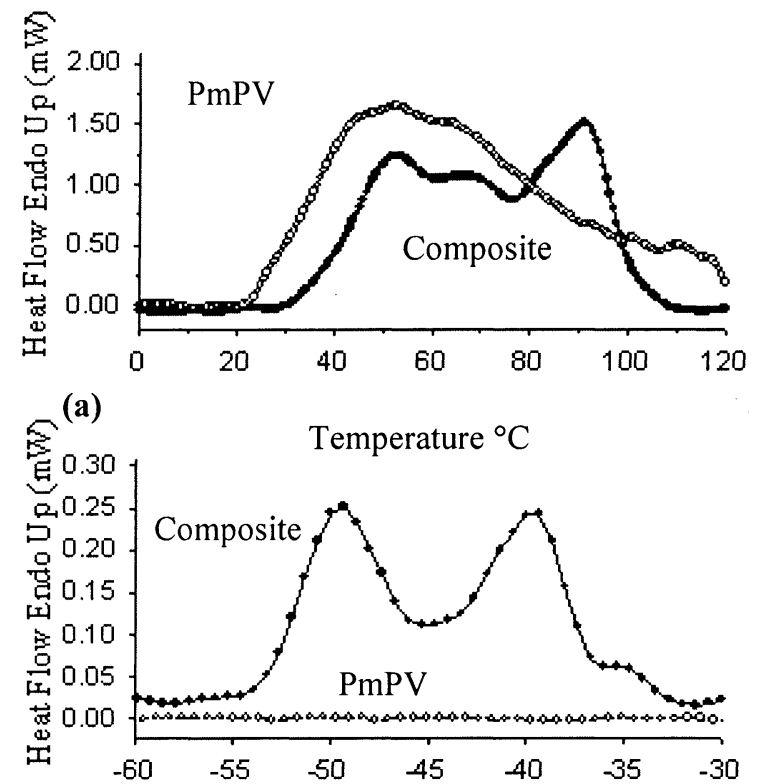

(b)

Temperature ${ }^{\circ} \mathrm{C}$

Fig 1 Thermogram of the SWNT composite film and the PmPV film for first run at (a); the high temperature regions and (b); the low temperatures regions.
The changes however to the polymer obsevered in the DSC seem to suggest a strong temperature dependence of this polymer-nanotube coupling. In addition to the changes in the high temperature regime a doubly peaked endotherm at $-49^{\circ} \mathrm{C}$ and $-39^{\circ} \mathrm{C}$ is observed in the composite as shown in fig $1(\mathrm{~b})$, which is not present in the first run of the pristine PmPV film. These transitions are of lower energy than that of the higher temperature transition. It has been previously suggested using atomistic molecular dynamic simulations that the polymer backbone provides the strongest binding to the nanotubes compared to the octyloxy side chains, which is around four times smaller in binding energy [5]. Hence it may be suggested that these lower temperature features arise from the influence of the nanotubes on the polymer side chains i.e. the floppy octoloxy side chains in the composite gain some additional degree of order when dispersed in nanotubes. It is proposed that investigation of the polymer interaction using TD-spectroscopy in particular FTIR and Raman spectroscopy may help to distinguish changes in the side chains from those of the backbone as a consequence of the nanotube polymer environment. It should be noted that the DSC of raw nanotubes shows no transitions within these temperature regions.

In fig 2 the observed structure of the Raman Gline is a result of the superposition of both metallic and semiconducting type nanotubes with different diameters, which has been reported previously for HiPco tubes [9]. The high frequency component of the $G$ line has been fitted using Lorentzian line shapes describing semiconducting tubes [10]. The shape of the lower frequency metallic mode has been described by the BreitWigner-Fano (BWF) function $\left(I(\omega)=I_{o}\left\{1+\left(\omega-\omega_{o}\right) / q \Gamma\right\}^{2} /\right.$ $\left\{1+\left[\left(\omega-\omega_{0}\right) / \Gamma\right]^{2}\right\}$, where $I_{o}, \omega_{o}, \Gamma$, and $q$ are intensity, the BWF peak frequency, broadening parameter, and the asymmetry parameter respectively [11]. As the temperature is increased the line shapes broaden and downshift, which has been reported previously for all modes in the Raman spectrum [12]: The frequency downshift has been mainly attributed to softening on the $\mathrm{C}-\mathrm{C}$ bond, which results in thermal expansion of the material upon temperature increase [13]. There are no other strong changes in the raw nantoube G-line spectra and shifting is reversible, in this temperature range.

Fig 2(c) presents the PmPV sample, fitted with 6 Lorentzian line shapes at $-35^{\circ} \mathrm{C}$ and $60^{\circ} \mathrm{C}$. The vibrational spectroscopy of PmPV is dominated by multiple modes around $1600 \mathrm{~cm}^{-1}$, where the dominant mode at $1592 \mathrm{~cm}^{-1}$ has been assigned to stretches within the phenyl ring [4]. The most dramatic change in the polymer upon increase in temperature is the broadening of the frequency distribution and decrease in relative intensity of the $A_{g}$ phenyl stretch modes at $1555 \mathrm{~cm}^{-1}$ and $1573 \mathrm{~cm}^{-1}$, which is also observed in the PmPV spectra at excitation wavelength $632.8 \mathrm{~nm}$ (not shown) [14]. Subsequently a change in the relative intensity of the $\mathrm{C}=\mathrm{C}$ vinyl stretch on the backbone at $1626 \mathrm{~cm}^{-1}$ [15], which up shifts to $1630 \mathrm{~cm}^{-1}$ is also observed. On cooling the pristine PmPV 
sample does not replicate its original spectrum and in particular the cis to trans ratio decreases, showing an increase in crystallinity of the polymer sample as a consequence of heating [14].

In fig 2(b) the temperature dependence of the Raman spectrum of the composite is illustrated. Similar to the raw HiPco spectra, metallic and semiconducting contributions are observed at both temperatures. At $-35^{\circ} \mathrm{C}$ strong contributions from the polymer backbone are observed, especially with the presence of the intense mode at $1630 \mathrm{~cm}^{-1}$. However the fwhm of each mode has decreased compared to the raw sample, which has been reported previously and is due to the decreased interaction between individual tubes [4][6].

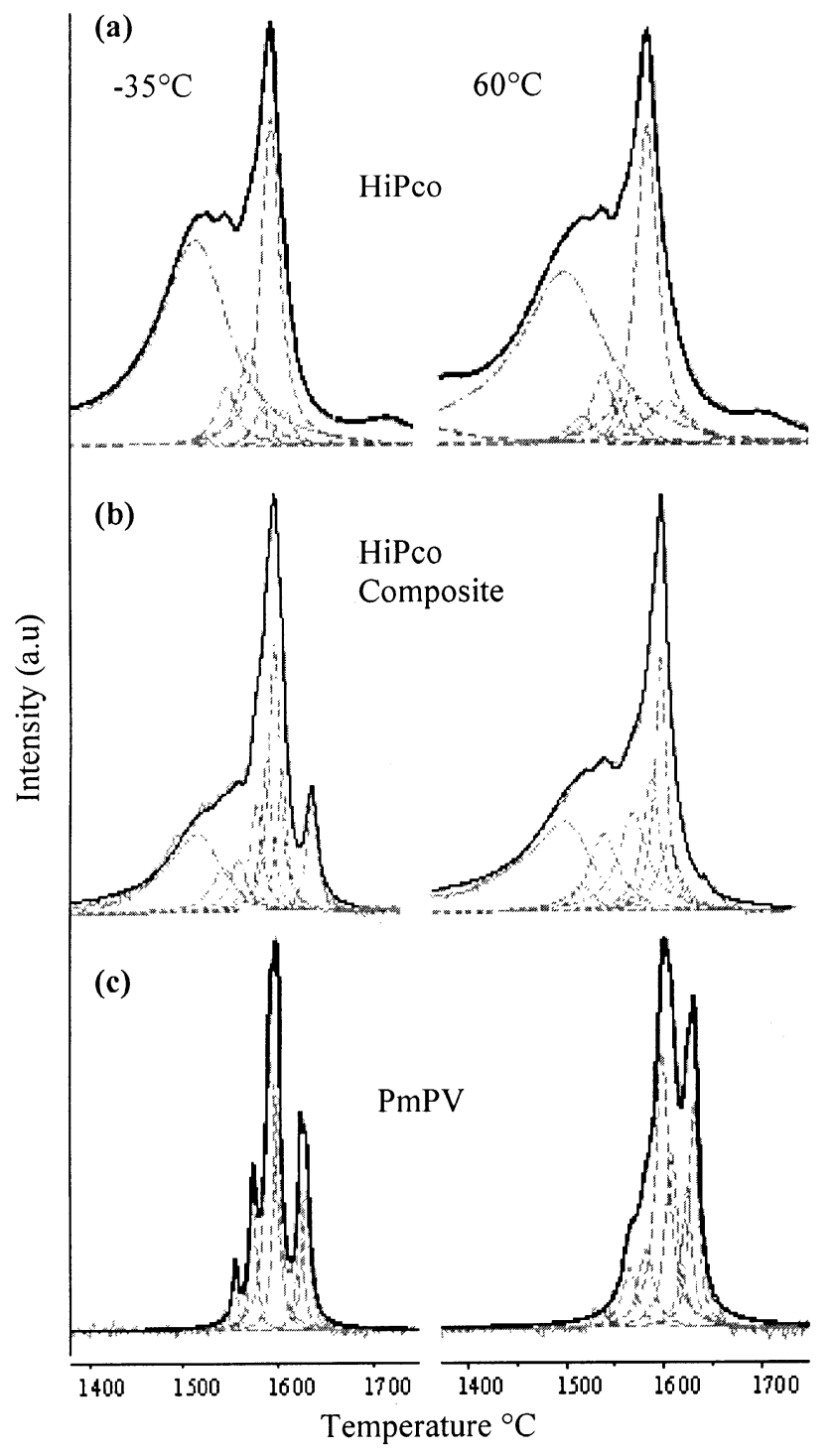

Fig 2. Temperature Dependent Raman spectra at $514.5 \mathrm{~nm}$ at $-35^{\circ} \mathrm{C}$ and $60^{\circ} \mathrm{C}$ of (a); Raw HiPco (b); $0.1 \%$ HiPco Composite and (c); PmPV
Upon increase in temperature to $60^{\circ} \mathrm{C}$ the polymer phenyl modes around $1555 \mathrm{~cm}^{-1}$ and $1573 \mathrm{~cm}^{-1}$ become damped and the Raman spectrum is dominated by nanotubes. The vinyl mode at $1630 \mathrm{~cm}^{-1}$ broadens and decreases in intensity. Changes appear to be governed by the disruption to the polymer backbone, which is also observed at laser excitation $632.8 \mathrm{~nm}$ (not shown) at this temperature [14]. This disruption permits an increase in the tangential vibration of the nanotube backbone, thus altering the spectral properties of the composite upon temperature increase.

In fig 3 the relative intensity of the BWF mode divided by the vinyl mode at $1630 \mathrm{~cm}^{-1}$ in the composite was graphed as a function of temperature. It is assumed that only nanotubes contribute to the BWF mode in the composite and only the polymer contributes to the "vinyl" mode in the composite. Upon increase in temperature above $40^{\circ} \mathrm{C}$ the spectral contribution from the nanotube increases substantially, where at $60^{\circ} \mathrm{C}$ the ratio of spectral contribution of tube to polymer is roughly $8: 1$. This abrupt rise is similar to the transition in the DSC at $\sim 60^{\circ} \mathrm{C}$. This abrupt change in the relative contribution is interpreted as a dissociation of the polymer from the tube, reducing the damping of the nanotube tangential modes. Although the relative contributions from the cis and trans modes of the polymer are not discernable in the more complex composite spectrum, upon cooling the relative intensities do not return to their original positions [14]. This indicates that the nanotube-polymer backbone binding has been altered upon cooling. If the composite is governed by the behaviour of the polymer at a specific temperature this indicates an increase in crystallinity of the polymer within the composite as all trans PmPV has been shown to facilitate polymer-tube binding while all cis conformations cause polymer aggregation which inhibits polymer-tube interaction [5]. No significant changes in relative intensities to the composite backbone appear to occur in the lower temperature region.

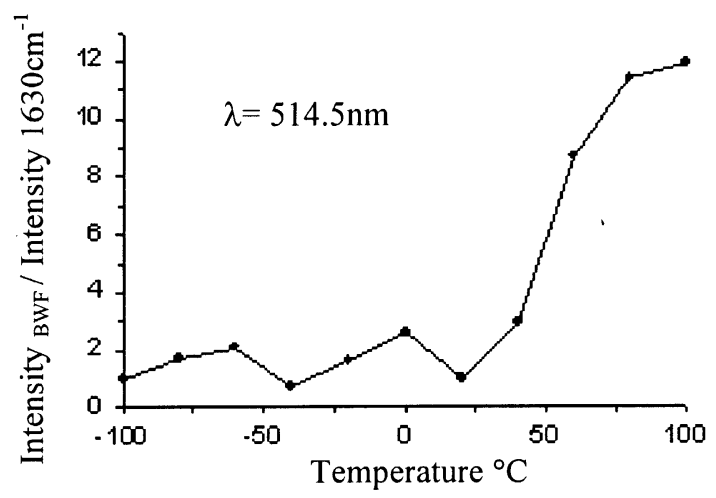

Fig 3. Intensity BWF/ Intensity $1630 \mathrm{~cm}^{-1}$ as a function of temperature for HiPco composite at $514.5 \mathrm{~nm}$

Temperature dependent infrared spectroscopy was carried out on all samples. The FTIR spectrum of 
carbon nanotubes (not shown) agreed with literature [16] three main features at $1600 \mathrm{~cm}^{-1}, 1400 \mathrm{~cm}^{-1}$ and $1180 \mathrm{~cm}^{-1}$ which have been attributed to the $\mathrm{C}-\mathrm{C}$ and $\mathrm{C}=\mathrm{C}$ stretching along the hexagonal array of the nanotube backbone, were observed [16]. In fig 4 the composite IR spectrum is dominated by the polymer and the nanotube modes within this wavelength range are overshadowed. Strong contributions from the polymer octyloxy side chains are seen. In particular the aryl-oxide stretch between $1230 \mathrm{~cm}^{-}$ 1 and $1270 \mathrm{~cm}^{-1}$ and the alkyl-oxide stretch between $1020 \mathrm{~cm}^{-1}$ and $1075 \mathrm{~cm}^{-1}$ are observed. For both the polymer and the composite these peak positions shift to a lower wavenumber as the temperature increases [14].

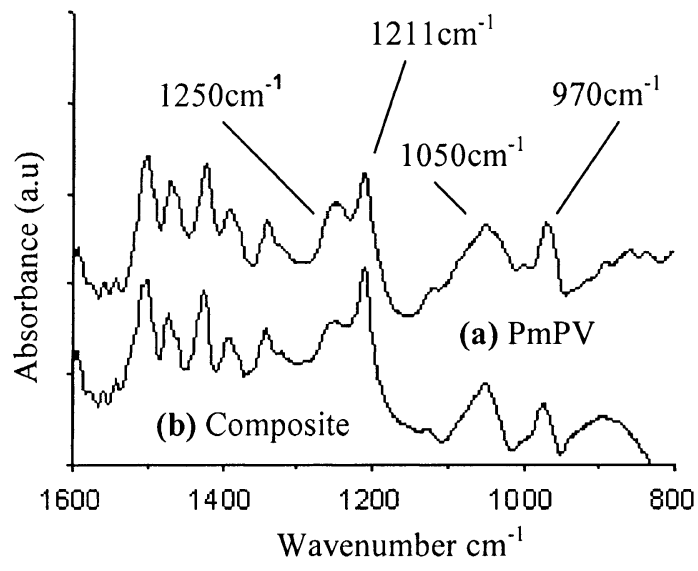

Fig 4. Infrared spectrum at ambient temperatures for (a) PmPV, (b) $0.1 \%$ HiPco composite.

In fig 5 the absorbance of the aryl-oxide stretch is graphed as a function of temperature for both PmPV and the composite for the first heating cycle at the lower temperatures. The side chains shows no changes for the polymer, however the composite graph shows an abrupt decrease in absorbance at about $-40^{\circ} \mathrm{C}$. This further suggests that transitions in the DSC at the lower temperatures originate from the side chains

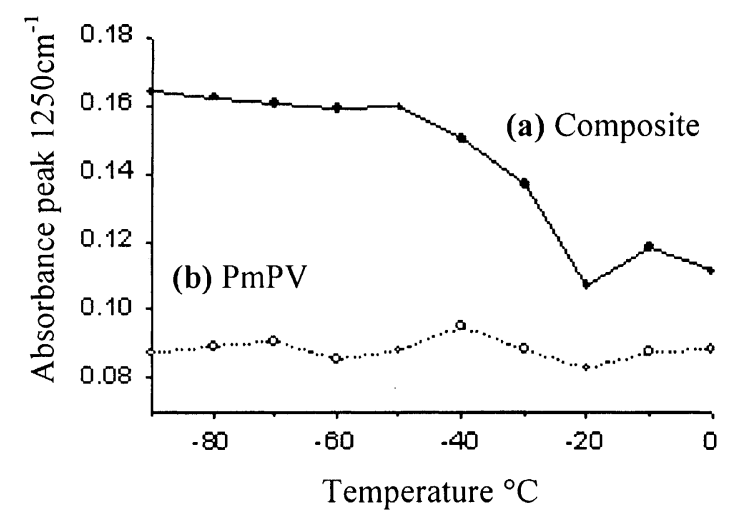

Fig 5. Absorption of the aryl-oxide stretch around $1250 \mathrm{~cm}^{-1}$ as a function of temperature for (a); the composite and (b); PmPV for first heating cycle only.

\section{Conclusions}

Modifications to the vibrational spectra of the polymer and composite are observed with a change in temperature. The IR of the composite shows an abrupt change in the absorbance of the octyloxy side chains at $-40^{\circ} \mathrm{C}$, and such modifications may help to explain the doubly peaked transitions in the DSC at the lower temperatures. Upon heating the composite from $-35^{\circ} \mathrm{C}$ to $60^{\circ} \mathrm{C}$ the Raman of the composite becomes abruptly dominated by nanotubes, suggesting that the polymer backbone dissociates and the nanotube tangential modes are no longer damped. The irreversibility of the process supports proposals that temperature cycling increases the crystallinity of the polymer seeded by the binding to the nantube [8].

\section{Acknowledgments}

FOCAS is funded through NDP 2000-2006 with support from the EU Development fund. SMK acknowledges DIT Scholarship support, S. Maier, TCD for PmPV.

\section{References}

[1] R. Saito, G Dresselhaus, M.S. Dresselhaus, Physical Properties of Carbon Nanotubes (Ed.), Imperial College Press, London, 1999.

[2] E. Kymakis, I. Alexandou, G.A.J. Amaratunga, Synthetic. Met. 127 (2002), 59-62.

[3] A. B. Dalton, S. Collins, E. Munoz, J.M Razal, V.H. Ebron, J.P. Ferraris, J.N Coleman, B.G. Kim, R.H Baughman. Nature, 423 (2003), 703

[4] A. B. Dalton, C. Stephan, J.N. Coleman, B. McCarthy, P.M. Ajayan, S. Lefrant, P. Bernier, W.J. Blau, H.J Byrne, J.Phys.Chem.B, 104 (2000), 10012.

[5] M.I.H. Panhuis, A. Maiti, A.B. Dalton, A. van der Noort, J.N Coleman, B. McCarthy, W.J Blau, J. Phys. Chem. B, 107 (2003), 478.

[6] S.M. Keogh, T.G Hedderman, E. Gregan, G. Farrell, G. Chambers, H.J Byrne, J. Phys. Chem. B, (available on web April 1, 2004) in press.

[7] S. Lefrant, I. Baltog, M.L. de la Chapelle, M. Baibarac, G. Louarn, C. Journet, P. Bernier, Synthetic. Met. 100 (1999), 13.

[8] K.P. Ryan, S.M. Lipson, A. Drury, M. Cadek, M. Ruether, S.M. O'Flaherty, V. Barron, B. McCarthy, H.J. Byrne, W.J. Blau, J.N. Coleman, Chem.Phys.Lett, 391, (2004), 329-333.

[9] A. Kukovez, C. Kramberger, V. Georgalilas, M. Prato, H. Kuzmany, The European Phys. J. B, 28, (2002), 223-230,

[10] A. Jorio, A.G. Souza Filho, G. Dresselhaus, M.S. Dresselhaus, A.K. Swan, M.S. Unlu, B.B. Goldberg, M.A. Pimenta, J.H. Hafner, C.M. Lieber, R. Saito, Phys. Rev. B. 65 (2002), 155412.

[11] S.D.M. Brown, A. Jorio, P Corio, M.S. Dresselhaus, G. Dresselhaus, R. Saito, K. Kneipp, Phys. Rev. B. 63 (2001), 155414

[12] F. Huang, K.T. Yue, P, Tan, S.L. Zhang, J.Appl, Phys, 84 (1998) $4022-4024$.

[13] N.R Raravikar, P. Keblinski, A.M. Rao, M.S. Dresselhaus, L.S Schadler, P.M. Ajayan, Phys. Rev. B, 66,(2002), 235424

[14] S.M. Keogh, T.G Hedderman, M. Ruether, E. Gregan, G. Farrell, G. Chambers, H.J Byrne, submitted J. Phys. Chem. B (2004)

[15] I. Orion, J.P. Buisson, S. Lefrant, Phys. Rev. B. 57, (1998), 4050.

[16] C. Branca, C. Corsara, F. Frusteri, V. Magazu, A. Mangione, F. Migliardo, U. Wanderlingh, Diamond and Related Materials, 13, (2004)1249-1253 